\title{
Remdesivir and Cardiovascular Safety Issues: Beyond the Treatment of COVID-19.
}

\author{
Fernando Mesta' and Livan Delgado-Roche ${ }^{2 *}$ \\ 'Department of Occupational Health, Safety and Hygiene Research, National Medicine and Homeopathy School of the National Polytechnic \\ Institute. Mexico City, Mexico. \\ ${ }^{2}$ Medical Direction, Laboratories Liomont S.A. de C.V. Mexico City, Mexico. \\ *Address for Correspondence: Livan Delgado-Roche, PharmD, PhD; Direction Medical, Laboratories Liomont S.A. de C.V., \\ Cuajimalpa de Morelos 05340, Ciudad de México, México, Tel: (+52-55) 58141510; E mail: Idelgado@liomont.com.mx
}

Received: 25 July 2020; Accepted: 14 August 2020; Published: 14 August 2020

Citation of this article: Delgado-Roche L, Fernando M (2020) Remdesivir and Cardiovascular Safety Issues: Beyond the Treatment of COVID-19. Rea Int J of Card and Cardio Med. 1(1): 006-004. DOI: 10.37179/rijccm.000002.

Copyright: (C) 2020 Delgado-Roche L, et al. This is an open access article distributed under the Creative Commons Attribution License, which permits unrestricted use, distribution, and reproduction in any medium, provided the original work is properly cited.

\section{Letter to Editor}

\section{Dear Editor}

Remdesivir is an adenosine nucleotide prodrug that is metabolized to the pharmacologically active nucleoside triphosphate metabolite after being distributed into cells. The drug acts as an adenosine triphosphate analog and competes for incorporation into RNA chains by the SARS-CoV-2 RNA-dependent RNA polymerase, resulting in delayed chain termination during viral RNA replication [1].

Remdesivir effectively inhibited SARS-CoV-2 infected Vero cells in vitro study [2]. Moreover, remdesivir was found to be a potent inhibitor of SARSCoV- 2 replication in human nasal and bronchial airway epithelial cells [3]. These outcomes encouraged the compassionate-use remdesivir in patients with SARS-CoV-2 infection (COVID-19), in the absence of any effective treatment.

The clinical assessment started with a cohort of patients hospitalized for severe Covid-19 who were treated with compassionateuse remdesivir, in which clinical improvement was observed in 36 of 53 patients (68\%) [4]. Thereafter, the first double-blind, placebocontrolled, randomized trial conducted with remdesivir versus placebo $(n=236)$ in severe COVID-19 patients, Wang and coworkers found no significant difference in primary outcome of time to clinical improvement within 28-days either in intention-to-treat analysis (median 21 days in remdesivir vs. 23 days in placebo arm; HR 1.23; 95\%CI, 0.87 to 1.75 ) or in the per-protocol analysis (median 21 days in remdesivir vs. 23 days in placebo arm; HR 1.27, 95\%CI; 0.89 to 1.80) [5]. As of 29 April 2020, preliminary results from the Adaptive COVID-19 Treatment Trial (ACTT) was communicated.
This was a multicenter, adaptive, randomized double-blind controlled trial aimed to evaluate the safety and efficacy of remdesivir for the treatment of non-severe COVID-19 $(n=800)$. The study showed a significant "positive effect" in diminishing time to recovery from 15 days to 11 days. However, the mortality rate of remdesivir vs placebo ( $8 \%$ vs $11 \%)$ was not statistically significant [6].

In the other face: the safety of remdesivir. Serious adverse events included acute kidney injury, septic shock and multiorgan failure have been reported. In addition, hypotension, cardiac arrest, hyponatremia, atrial fibrillation, hypersensitivity including infusionrelated and anaphylactic reactions [1]. Wang et al. reported similar proportion of adverse events in remdesivir (66\%) and control arm (64\%). However, serious adverse events reported in $18 \%$ vs. $26 \%$ in remdesivir compared with controls, respectively.

A high proportion of patients from the remdesivir group discontinued the treatment (12\%) compared to the control arm (5\%), either because of adverse events or serious adverse events [5]. On the other hand, in SIMPLE clinical trial, grade 3 or higher liver enzyme elevations occurred in $7.3 \%$ of patients, while $5 \%$ in 5 -days arm and $10 \%$ in 10-days arm had to withdraw from remdesivir due to severe adverse events [7].

Until now, the cardiovascular safety of remdesivir is unclear, as well the potential underlying mechanisms. COVID-19 itself has been associated with cardiovascular damage, meanwhile cardiovascular risk factors may be associated with poor outcome in COVID-19 patients [8]. Therefore, post-marketing surveillance programs focused on the risk/benefit balance of remdesivir is of major relevance. 
Citation: Delgado-Roche L, Fernando M (2020) Remdesivir and Cardiovascular Safety Issues: Beyond the Treatment of COVID-19. Rea Int J of Card and Cardio Med. 1(1): 006-004. DOI: 10.37179/rijccm.000002.

In conclusion, while the encouraging preclinical and clinical studies seem to suggest a clinical benefit from remdesivir in severe COVID-19, remdesivir should be used with caution until safety concerns will be better understood, and post marketing surveillance or pharmacovigilance showed additional information.

\section{References}

1. Singh AK, Singh A, Singh R, Misra A (2020) Remdesivir in COVID-19: A critical review of pharmacology, pre-clinical and clinical studies. Diabetes Metab Syndr Clin Res Rev 14: 641-648. Link: https://bit.ly/2Cq0XPo

2. Wang M, Cao R, Zhang L, Yang X, Liu J, et al. (2020) Remdesivir and chloroquine effectively inhibit the recently emerged novel coronavirus (2019-nCoV) in vitro. Cell Res 30: 269-271. Link: https://go.nature.com/3fV61cq

3. Andrés $P$, Blandine $P$, Thomas J, Sophie TA, Aurélien $T$, et al (2020) Characterization and treatment of SARS-CoV-2 in nasal and bronchial human airway epithelia. Biorxiv 1: 100059. Link: https:// bit.ly/2E2b5OV
4. Grein J, Ohmagari N, Shin D, Diaz G, Asperges E, et al. (2020) Compassionate use of remdesivir for patients with severe Covid-19. N Engl J Med 382: 2327-2336. Link: https://bit.ly/2XYBxQx

5. Wang Y, Zhang D, Du G, Du R, Zhao J, et al. (2020) Remdesivir in adults with severe COVID-19: a randomised, double-blind, placebocontrolled, multicentre trial. Lancet 395: 1569-1578. Link: https:// bit.ly/3aocN98

6. (2020) NIH clinical trials Remdesivir accelerates recovery from advanced COVID-19 29. Link: https://bit.ly/2DU84jV

7. (2020) Study to evaluate the safety and antiviral activity of remdesivir (GS-5734 ${ }^{\mathrm{TM}}$ ) in participants with moderate coronavirus disease (COVID-19) compared to standard of care treatment. Link: https://bit.ly/3aoV5Th

8. Mehra MR, Desai SS, Kuy SR, Henry TD, Patel AN (2020) Cardiovascular disease, drug therapy, and mortality in COVID-19. N Engl J Med 382: E102. Link: https://bit.ly/3klbDKz 